\title{
Conceptualización y marco analítico explicativo del multilateralismo latinoamericano
}

Rita Giacalone*

\section{RESUMEN}

Este artículo resume las principales conceptualizaciones del multilateralismo latinoamericano que aparecen en la literatura, a fin de identificar sus contribuciones y debilidades. A partir de esa identificación, se propone un proceso alternativo para conceptualizarlo que incluye variables descriptivas y explicativas, y tiene en cuenta el contexto del sistema regional, así como los intereses de los poderes regionales y otros actores estatales. El objetivo es evaluar si existe un marco analítico propio para el estudio del multilateralismo en América Latina.

Palabras clave: multilateralismo, regionalismo, marco analítico, orden regional, actores estatales.
Conceptualization and explanatory analytical framework of Latin American multilateralism

\section{ABSTRACT}

This article summarizes the main concepts of Latin American multilateralism found in literature, with the aim of identifying both their contributions and weaknesses. This identification serves as the basis to propose an alternative process of conceptualization that includes not only descriptive variables but also explanatory ones, and takes into account the regional system, and the national interests of state actors. The objective is to evaluate if

* PhD en Historia de Indiana University. Docente Investigadora, Facultad de Ciencias Económicas y Sociales, Universidad de los Andes, Mérida (Venezuela).

ritagiacalone@yahoo.com

Recibido: 14 noviembre de 2015 / Modificado: 4 de diciembre de 2015 / Aceptado: 19 de junio de 2016

Para citar este artículo

Giacalone, R. (2016). Conceptualización y marco analítico explicativo del multilateralismo latinoamericano. OASIS, 24, 7-25.

DOI: http://dx.doi.org/10.18601/16577558.n24.02 
there is a specific analytical framework for the study of Latin American multilateralism.

Keywords: Multilateralism, regionalism, analytical framework, regional powers, state actors.

\section{INTRODUCCIÓN}

Este artículo resume las principales conceptualizaciones del multilateralismo latinoamericano en la literatura a fin de identificar sus contribuciones y debilidades. A partir de esa identificación, se propone un proceso alternativo para conceptualizarlo, que incluye variables descriptivas y explicativas, teniendo en cuenta el contexto del sistema regional, así como los intereses de los poderes regionales y otros actores estatales. El objetivo es evaluar si existe un marco analítico propio para el estudio del multilateralismo en América Latina.

\section{EL MULTILATERALISMO}

\section{LATINOAMERICANO EN LA LITERATURA}

Buena parte de los intentos por conceptualizar el multilateralismo latinoamericano se basan en una identidad común, valores tradicionales (p. ej.: autonomía frente a EE.UU.) y continuidad de procesos históricos del siglo XIX, como la aspiración a la unión política y a la integración regional. Esto determina que para Sanahuja (2012), el multilateralismo latinoamericano sea defensivo y autonomista. Otros le atribuyen características como debilidad institucional, vocación política y presidencialismo (Legler y Santa Cruz, 2011), o destacan a la diplomacia de cumbres como etapa preparatoria para desarrollar un proyecto estratégico de región, la Comunidad de Estados Latinoamericanos y del Caribe (CELAC) (Rojas Aravena, 2011). Esta se asienta en la generación de consenso político, el incremento de la interconexión y el fomento de la interdependencia, con poco desarrollo jurídico e institucional, y asumiendo el patrimonio del Grupo de Rio y de la Cumbre de América Latina y el Caribe sobre Integración y Desarrollo (CALC) (2012, p. 21).

Ya sea que se asuma a priori un conjunto de requisitos (identidad común, aspiración de unión política, etc.) para que un acuerdo sea multilateral o que estos deriven de la observación de acuerdos considerados multilaterales, la literatura reconoce un único patrón de multilateralismo latinoamericano y lo distingue de acuerdos de integración económica basados en el modelo europeo: Comunidad Andina (CAN), Comunidad del Caribe (CARICOM), Sistema de Integración Económica Centroamericana (SIECA), Mercado Común del Sur (Mercosur).

En esta línea se ubica Sanahuja (2012, p. 22), que consideraba que América Latina enfrentaba un "trilema" entre la defensa de la soberanía del Estado-nación, la aspiración de integración regional y la búsqueda de autonomía internacional, vinculado con su ambivalente relación con Estados Unidos. Si bien el rechazo del regionalismo abierto servía de base a los gobiernos latinoamericanos para proponer una mayor autonomía en su accionar internacional y en sus políticas de desarrollo frente a Estados Unidos, el nacionalismo y un institucionalismo débil conspiraban contra el logro de ese objetivo. 
Desde los años ochenta hubo intentos de coordinar posiciones fuera de la Organización de Estados Americanos (OEA) en relación con la crisis centroamericana (Grupo Contadora, del cual surgió el Grupo de Rio), con carácter más político que económico, mientras antes el regionalismo buscaba la autonomía económica mediante el desarrollo a través de la protección arancelaria. En los ańos noventa surgió un "nuevo regionalismo" que buscaba reforzar la autonomía internacional de la región y su capacidad interna de gobernabilidad (Sanahuja, 2012, p. 25). Este adquirió un fuerte carácter de racionalidad política y se convirtió en una estrategia para enfrentar a la globalización aunque coexistía con un regionalismo abierto de orden económico, y Chile y México optaban por estrategias individuales. A mediados de la primera década del siglo XXI se ampliaron las opciones de negociación extrarregional para los países latinoamericanos, que experimentaron con distintos tipos de acuerdos comerciales (regionales, Sur-Sur y Norte-Sur) para maximizar sus opciones económicas dentro de la incertidumbre generada por el estancamiento de la Ronda Doha de la Organización Mundial de Comercio (OMC). Esta dispersión significó la crisis y el fracaso del regionalismo abierto (pp. 20-21).

Desde 2005, el panorama regional estuvo dominado por gobiernos de izquierda que cambiaron la orientación de la integración. América Latina pasó a preferir un regionalismo posliberal aprovechando que Estados Unidos estaba ocupado con problemas extrarregionales (Sanahuja, 2012, p. 31). Esto se manifestó no en las políticas comerciales (que siguieron divididas entre viejo regionalismo y regionalismo abierto), sino en las que adoptaron la Alianza Bolivariana para Nuestra América (ALBA) y la Unión de Naciones Suramericanas (UNASUR). Estos acuerdos proponen el retorno de la política a las relaciones internacionales; del desarrollismo y del Estado a la economía y a la política; una mayor autonomía; el énfasis en instituciones, políticas y problemas comunes; atención a lo social y a las asimetrías, y la inclusión de actores no gubernamentales (pp. 32-33). En este contexto, la Comunidad Suramericana de Naciones (CSN) (2004) recreó el ideal tradicional de la integración regional latinoamericana, acotada a Suramérica por los imperativos geopolíticos de Brasil (2012, p. 35). Esta convergencia de expectativas e intereses en la CSN no significó una visión compartida de región (p. 38). Por ello, se la transformó en UNASUR (2008), dando un salto del regionalismo abierto al regionalismo posliberal, al darse preferencia a las agendas políticas, sociales y de defensa y seguridad sobre la económica.

De todas maneras, la diversidad de enfoques y estrategias dentro de UNASUR imposibilita que contribuya a una mayor participación de Suramérica en estructuras de gobernanza global $^{1}$, lo que Sanahuja (2012, p. 42) atribuía también a la ambivalencia de Brasil, que oscila entre usarla como instrumento de

Sanahuja (2012) no define esta gobernanza, asumiendo por tanto que es un concepto unívoco, a pesar de que ha sido problematizado por distintos autores. Véase Dingwerth y Pattberg (2006). 
proyección global y actuar individualmente fuera de la región. En lo interno, UNASUR se ve debilitada porque la integración energética y la infraestructura constituyen parte de los intereses y preferencias nacionales, y pueden ser fuentes de conflicto (pp. 43-45). La integración en seguridad y defensa responde al interés brasileño por controlar sus fronteras frente a la inestabilidad política y las actividades ilícitas en la subregión andina, además de asegurarle el rol de mediador en las crisis regionales (p. 48).

Aunque Sanahuja destacaba la precariedad institucional de UNASUR y el riesgo que representa su presidencialismo exacerbado, consideraba que ALBA y UNASUR estaban redefiniendo el espacio político latinoamericano, su identidad y su sentido de región (2012, pp. 55-58). En cuanto a la CELAC, esta tiene la misma función de gestión de crisis y defensa de la democracia que la OEA y la UNASUR, con lo que se corre el riesgo de un solapamiento de instituciones y mandatos. En su interpretación, es un mecanismo no institucionalizado de consulta política, que forma un círculo concén trico en torno a UNASUR y al MERCOSUR para incorporar al Caribe y Centroamérica. Aquí parece pertinente el comentario de Goh (2014) sobre el sudeste asiático, donde los actores cooperan en distintos grupos sin generar juegos de suma cero, pero sin que exista un verdadero orden regional, que requiere un acuerdo institucionalizado acerca de cons- treñimientos, reglas de conducta y resolución de conflictos, que no puede desarrollarse con instituciones débiles.

En 2014, Sanahuja (2014, p. 76) reconoció, sin embargo, que América Latina no responde a la "imagen unionista o neobolivariana de una región que deja atrás el neoliberalismo y afirma colectivamente su autonomía en un mundo post-hegemónico”. Esto le llevó a explorar en detalle a la UNASUR y la CELAC, considerándolas los acuerdos de concertación política y gobernanza regional más relevantes ${ }^{2}$. En una tipología del multilateralismo -hegemónico si lo promueve Estados Unidos; normativo si lo hace la UE; defensivo si es impulsado por países en desarrollo y revisionista, si lo es por países emergentes (2013, p. 27) -, ubica a CELAC en la modalidad defensiva basada en el respeto de la soberanía nacional y la no intervención (2014, p. 97). Estos rasgos surgen de las narrativas del Movimiento de No Alineados y el Grupo 77, donde predominan países de AsiaPacífico, África y el Caribe, descolonizados en la segunda mitad del siglo xx (Sanahuja, 2013, p. 42), cuya experiencia histórica y cultural es distinta de la de los latinoamericanos. Además, estas modalidades se dan en el multilateralismo como discurso político, diferente del "realmente existente" (2013, p. 31), y se ubica a UNASUR y la CELAC como acuerdos regionales que apoyan el multilateralismo revisionista de los poderes emergentes, quienes reclaman

2 Sanahuja (2014, pp. 82, 87, 99) plantea ahora una visión más positiva del regionalismo abierto, basándose en sus logros económicos (inserción internacional, aumento del comercio intrarregional y desarrollo incipiente de cadenas productivas) y reconoce que el regionalismo abierto se agotó solo "para algunos países". 
mayores cuotas de poder global sin abandonar sus intereses nacionales (p. 45).

En 2011, Legler y Santa Cruz plantearon como rasgos del multilateralismo latinoamericano el presidencialismo, el énfasis en la concertación política y la débil institucionalidad. Consideraron a ALBA, UNASUR y CELAC ejemplos de acuerdos multilaterales y propusieron incorporar el caso latinoamericano al estudio del multilateralismo en relaciones internacionales. Destacaban que para los enfoques institucionalistas estos acuerdos reducen los costos de transacción en las relaciones entre Estados al conformar burocracias más eficientes que las nacionales y constituirse en árbitros imparciales de conflictos entre miembros, con lo cual favorecen la cooperación, mientras para los realistas estos acuerdos son arenas de luchas de poder entre países grandes y pequeños, lo que se traduce en estudios que ven al multilateralismo como instrumento de gobernabilidad regional o producto del interés nacional de Estados grandes (Legler y Santa Cruz, 2011, p. 15). En esta perspectiva, la Celac sería un mecanismo de México para contrarrestar el peso regional de Brasil y Venezuela, y su exclusión de Suramérica. De acuerdo con enfoques constructivistas, el multilateralismo varía según el contexto en que se construye porque se basa en ideas o principios de aceptación generalizada, lo que determina que esté influenciado por la identidad, la cultura y las tradiciones regionales (Legler y Santa Cruz, 2011, pp. 17-18).

Previamente, Legler (2011, p. 33) planteaba que a medida que Estados Unidos prestaba menos atención a América Latina, era evidente la ausencia de elementos adhe- sivos para la cooperación regional debido a la heterogeneidad existente. Por ello, las instituciones multilaterales latinoamericanas debían pasar de afirmar su autonomía frente a actores externos a asumir la solución de problemas regionales prioritarios (p. 27).

Serbin (2010) asocia el proceso de cumbres presidenciales en la primera década del siglo XXI con la creación de foros multilaterales como la UNASUR y CALC, a los que considera distintos de instituciones multilaterales previas como el Sistema Económico Latinoamericano (SELA), la Asociación Latinoamericana de Integración (ALADI), el Grupo de Rio, etc. Los nuevos foros no tienen una visión o proyecto estratégico común y oscilan entre multilateralismo vinculante -si usan instituciones globales para restringir el poder regional de Estados Unidos-, de colaboración selectiva -si desarrollan lazos con este país para hacer frente a problemas comunes-, y de contención acotada -si excluyen a Estados Unidos y dan capacidad de negociación a la región- (pp. 11-12). La proliferación de foros deja en manos de los presidentes la toma de decisiones ad hoc según la urgencia de los problemas planteados, sin participación de la sociedad civil ni seguimiento de las medidas aprobadas (pp. 17-19).

Por su parte, Diamint (2013, p. 63) considera que UNASUR y ALBA no son proyectos multilaterales sino instrumentos de política exterior de Brasil y Venezuela, que buscan alcanzar objetivos nacionales antes que regionales. El argumento de Brasil para distanciarse de América Latina y establecer una relación privilegiada con Sudamérica nació de una operación de marketing para crear confianza en sus negociaciones de préstamos 
internacionales a fines de los ańos noventa, ya que "como rótulo, 'América Latina' dificultaba las negociaciones con banqueros, oficiales del tesoro y líderes políticos norteamericanos". Esta transformación se convirtió luego en una estrategia para proyectarse en el sistema internacional. Según Diamint (p. 63), Brasil respondió a la proyección venezolana hacia el Caribe mediante ALBA con la creación de la CALC (2008). Esta y la UNASUR son parte del proyecto brasileńo de armar coaliciones centradas en lo político, de manera que el mercado y el comercio sean temas secundarios y no condicionen su actuación global.

La estrategia de construir alianzas crea mayores instancias de participación para sus miembros y limita el poder de las naciones grandes. Esto se da en UNAsur, donde Brasil incorpora resoluciones de sus socios, aunque casi siempre modificadas. Esto es parte de la dinámica de esos acuerdos y no significa que UNASUR se haya alejado de la voluntad política de Brasil (p. 64). Si se agrega que su institucionalidad es débil, no hay voluntad política supranacional y el secretariado solo administra la agenda de los presidentes, la UNASUR no es un organismo multilateral sino una instrumento de política exterior que "confunde el Estado con el Ejecutivo” (p. 67).

Alba es aún menos institucionalizada, no tiene agenda fija de reuniones o temas y el presidente de Venezuela es el presidente "autoasignado" del acuerdo. Nació en rechazo al Área de Libre Comercio de las Américas (AL$\mathrm{CA})$, pero se volvió "un paso en la construcción de poder [regional]" para su fundador, Hugo Chávez. Que unasur y ALBA se estructuren con una lógica diferente de la de Comunidad
Andina de Naciones (CAN) y MERCOSUR no da pie para argumentar una visión idealizada de una identidad suramericana, ya que de existir alguna similitud entre ambos acuerdos sería que son expresión del personalismo y la inestabilidad política regional (Diamint, 2013, p. 75). Ni unasur ni alba son "instituciones de gobernanza regional, sino instituciones flexibles que se adaptan y acondicionan a los deseos de algunos presidentes" (p. 68), y tampoco "son referentes en la agenda internacional”. En cuanto a que constituyan "un modelo acabado de nuevo regionalismo fundado en una 'razón integradora' y con proyección eficaz a largo plazo" (Sanahuja, 2010, pp. 120-123), las divergencias internas en la primera y el peso del personalismo en ambas no asegura la continuidad o validez de estos acuerdos en el futuro.

La literatura sobre regionalismo también aporta al tema. En la CELAC, dos poderes regionales, Brasil y México, estuvieron “condicionados por sus respectivos espacios geopolíticos y modelos de inserción internacional" (Llenderrozas, 2013, p. 187). La CELAC se define a sí misma como el mecanismo representativo de América Latina y el Caribe en el sistema internacional, reemplazando al Grupo de Rio en la interlocución con la Unión Europea (UE) (p. 186). Aunque el regionalismo es una de sus metas, enfatiza el objetivo de fortalecer la vinculación con el entorno internacional, convirtiéndose en voz regional o actor político internacional para pronunciarse con respecto a grandes temas globales (cambio climático, etc.) (pp. 184-185).

Según Malamud (2015), el exceso de nacionalismo y la falta de liderazgo son pro- 
blemas que afectan al regionalismo latinoamericano, aunque se argumente la presencia de fuerzas externas (EE.Uu.) para justificar la falta de avance de la integración regional y de convergencia en las posiciones de sus gobiernos en la onu y la oea. Por ello, la UNASUR y la CELAC representan una "huida hacia adelante" ante la falta de acuerdo con respecto a ejes de integración y cooperación, objetivos y problemas comunes. Considerarlas resultado de una conjunción de gobiernos progresistas en la región contribuye a debilitarlas, no por el color político que puedan tener, sino porque implican una idea de uniformidad necesaria (p. 31).

En MERCOSUR existen distintas preferencias respecto a alineamientos geoeconómicos y geopolíticos con poderes extrarregionales -en Brasil hay interés por un acuerdo con la UE (Malamud, 2015, pp. 18, 23), mientras los países provenientes del Alba (Venezuela, Bolivia) y Argentina (hasta el cambio de gobierno en diciembre de 2015) prefieren relacionarse con China y Rusia (Yakovleva, 2014)-. Esto se corresponde con distintas visiones del futuro del sistema internacional para un poder regional como Brasil y poderes secundarios como Argentina y Venezuela. Malamud (2015, pp. 24-25) destaca los supuestos que sustentan el optimismo de estos últimos respecto al futuro: 1) la economía mundial marcha hacia un mundo dominado por países emergentes; 2) los países desarrollados perderán liderazgo tecnológico y empresarial; 3) el crecimiento de China mantendrá altos los precios de las materias primas en las próximas décadas; 4) los emergentes tienen un modelo de desarrollo basado en mercados internos y exportación de manufacturas y servicios; y 5) la transición no causará rupturas, conflictos, crisis medioambientales, lucha por recursos naturales o reacciones sociales. Pero, según Malamud, el futuro no es tan previsible ni a corto ni a mediano plazo.

Garzón (2015) se pregunta si el regionalismo resultará fortalecido o debilitado por una mayor presencia de poderes en un sistema internacional multipolar. Como muchos de ellos son poderes regionales, esto apoya la interpretación de que resultará fortalecido en un sistema internacional regio-céntrico, basado en una arquitectura de regiones (Buzan, 2004; Acharya, 2014, pp. 85-86). En él, los poderes emergentes permanecerán enraizados en sus regiones y las reorganizarán en su torno con un patrón eje-rayos de influencia económica, donde, relativamente aislados de influencias globales, adoptarán distintas formas de organización política (esferas de influencia, federaciones, etc. $)^{3}$. Pero para Garzón, la mul-

\footnotetext{
3 Mylonas y Yorulmazlar (2012) lo sintetizan en el concepto de multilateralismo regional, paradigma futuro que puede brindar paz y estabilidad a un sistema internacional en el cual Estados Unidos disminuye su compromiso y las organizaciones multilaterales tienen límites para enfrentar problemas como el cambio climático. La cooperación interregional es un elemento clave del multilateralismo regional, impulsada por la incapacidad de cualquier poder de enfrentar los problemas actuales aisladamente. La transición hacia ese sistema internacional será pacífica y ordenada si se estructura sobre acuerdos de integración regional, ya que se basará en paraguas de seguridad y áreas de comercio que beneficien a todos sus miembros.
} 
tipolaridad generará fuerzas centrífugas en las regiones porque la emergencia de nuevos actores globales producirá cambios en el análisis de costo-beneficio en los Estados menores. A este escenario alternativo lo denomina "multipolaridad descentralizada”, en la cual el grueso de los lazos económicos y políticos regionales no convergirá en los poderes regionales sino que trascenderá la región en todas direcciones. Esto se debe a dos mecanismos causales: la emergencia simultánea de nuevos polos de poder en distintas regiones y la propensión de los Estados pequeńos a minimizar el costo de acceder a los recursos externos (mercados, inversiones, ayuda) que necesitan.

El surgimiento de nuevos polos de poder implica mayor número de Estados con capacidad de proyectar poder en una o más regiones. No hay que asumir que un poder regional no desarrollará intereses extrarregionales (búsqueda de recursos naturales o nuevos mercados) o no buscará el apoyo de otras regiones en organizaciones internacionales para enfrentar a otro. Además, según Garzón (2015), los poderes regionales pueden proyectar poder fuera de su región con recursos distintos de los poderes grandes (p. ej.: cooperación técnica en etanol de Brasil en África).

Una política exterior adaptativa de los países pequeños puede buscar un equilibrio entre la necesidad de acceder a recursos externos y de mantener su autonomía política (Garzón, 2015). En la multipolaridad, algunos Estados pequeños pueden preferir cooperar con poderes distantes antes que caer bajo la influencia dominante de un poder regional, si esto les impide diversificar sus lazos económicos o incluye costos políticos a largo plazo como dependencia asimétrica y pérdida de libertad de acción. La multipolaridad puede hacer que países pequeños de una región respondan positivamente a fuerzas centrífugas provenientes de otras, sin dejar de tener lazos con su poder regional, solo que estos no serán exclusivos.

Garzón (2015) se apoya en la "teoría de la integración regional" y la "teoría del regionalismo abierto" (Mattli, 1999), que definen al regionalismo como un fenómeno global, reconocible en cualquier región, que responde a una estructura de incentivos o condiciones. En la primera teoría, las naciones de una región establecen instituciones supranacionales en las que delegan parte de su autoridad política o su soberanía sobre regulaciones domésticas. En la segunda, la apertura comercial se orienta a ganar competitividad para actuar en un contexto global liberalizado; no se busca comerciar entre ellos sino insertarse mejor en la economía internacional. Hay incentivos para el primer tipo de acuerdos cuando en los mercados regionales existen oportunidades de ganancias que contrarrestan la pérdida de autoridad política o soberanía, o existe un poder regional dispuesto a hacer pagos que compensen esas pérdidas. Sin estas condiciones, los Estados pequeños pueden preferir integrarse con poderes extrarregionales, si estos muestran interés en vincularse con ellos.

Garzón considera que este proceso se observa ya, y usa indicadores de Iapadre y Tajoli (2014, pp. 95-97) para medir el grado de regionalización comercial en MERCOSUR y otros acuerdos formados por poderes regionales. Los indicadores muestran que, aunque esos poderes aumentaron su presencia en el 
comercio global, no ocurrió lo mismo en sus regiones. A excepción de China, los poderes regionales emergentes se consolidaron como proveedores de su región y no como ejes económicos que absorben bienes primarios e insumos de sus vecinos para transformarlos en bienes terminados para el mercado internacional. Al medir la centralidad de la economía del poder regional en sus relaciones con países vecinos Chen y De Lombaerde (2014) encuentran que los suramericanos eran más dependientes de Brasil en el 2000 que en el 2010. La aplicación de un índice de globalización de los poderes regionales y sus vecinos reveló que esos poderes no tienen índices superiores a los de otros países de su región ya que todos parecen globalizarse al mismo ritmo (Chen y De Lombaerde, 2014, pp. 123-124). Resumiendo, una mayor integración de los poderes regionales en el sistema económico internacional no significa mayores importaciones de sus vecinos; por el contrario, esos poderes importan insumos extrarregionales para exportar bienes finales a sus vecinos. Esto implica que el desarrollo no marcha hacia un escenario multipolar en el que los poderes regionales impondrán la dinámica de regionalización a sus vecinos (Garzón, 2015).

Garzón (2015) observa que Bolivia, Colombia, Ecuador, Perú y Uruguay, naciones suramericanas pequeñas, otorgan prioridad a la diversificación de sus alineamientos con poderes extrarregionales (Perú y Colombia, con Ee.uu., la ue y China; Bolivia con China, Rusia e Irán, etc.), aunque se asocien con Brasil o Venezuela. Independientemente de la inclinación ideológica de sus gobiernos, coinciden en buscar la diversificación política y económica con actores extrarregionales. En resumen, si el sistema internacional se mueve hacia una multipolaridad descentralizada, las regiones no se organizarán en forma eje-rayos en torno a poderes regionales, sino que trascenderán sus límites para establecer lazos con poderes extrarregionales. En América Latina, las organizaciones regionales jerárquicas no van a desaparecer, pero tendrán que coexistir con una constelación de lazos extrarregionales.

\section{CONTRIBUCIONES Y DEBILIDADES DE LAS CONCEPTUALIZACIONES}

$\mathrm{Al}$ revisar las conceptualizaciones del multilateralismo latinoamericano en la literatura, se observa que sus contribuciones son:

1. No es ahistórico sino que evoluciona según la dinámica global y regional entre actores (Serbin; Legler y Santa Cruz).

2. Como está influenciado por la identidad, la cultura y las tradiciones regionales (Legler y Santa Cruz, Serbin), no existe un único patrón latinoamericano por las diferencias en términos de cultura y tradiciones regionales existentes (Malamud) y también pueden existir distintos patrones de multilateralismo, apoyados en distintas visiones de la futura organización del sistema internacional (Garzón).

3. Los estudios sobre regionalismo o multilateralismo/regionalismo como instrumentos de política exterior de actores regionales tienen mayor capacidad explicativa (Diamint, 2013; Malamud, 2015) que los que definen a ciertos acuerdos 
como multilaterales y explican la realidad a partir de sus rasgos, especialmente si estos son similares a los de acuerdos no multilaterales o no tienen respaldo en la realidad.

4. Hay diferencia entre el multilateralismo narrativo y el realmente existente (Sanahuja, 2014), que se observa en las diferencias entre acuerdos y también dentro de ellos con respecto a relacionamientos geoeconómicos y geopolíticos.

5. La CELAC tiene el potencial y la voluntad política de proyectar externamente a la región combinando intereses de dos poderes regionales, Brasil y México (Rojas Aravena; Llenderrozas).

6. La autonomía puede ser una aspiración del multilateralismo latinoamericano pero no exclusivamente frente a Estados Unidos, porque países pequeños o medianos pueden buscar autonomía frente al poder regional.

En cuanto a las debilidades observadas:

1. Algunas conceptualizaciones son puramente descriptivas y ubican bajo el mismo concepto a la CSN, UNASUR y
ALBA, caracterizadas más por sus objetivos diferentes (comercio preferencial, estabilidad política y defensa ideológica, respectivamente) que por sus similitudes.

2. La divergencia en orientaciones extrarregionales dentro de los acuerdos cuestiona la importancia de la concertación política más allá de la voluntad de disminuir los conflictos.

3. El argumento de que la firma de acuerdos Norte-Sur significó la crisis y el fracaso del regionalismo abierto es débil porque un objetivo de este es profundizar y hacer eficaz su inserción internacional mediante esos acuerdos. En 2005, el giro hacia el desarrollismo y estatismo ${ }^{4}$ se dio en MERCOSUR Y ALBA, pero en la CAN, el SIECA, CARICOM y países como Chile y México se mantuvo el regionalismo abierto y se firmaron acuerdos Norte-Sur. El argumento acerca del fin del regionalismo abierto surge de extrapolar la experiencia del Cono Sur y ALBA como representativa de toda la región.

4. Aunque recientemente Sanahuja (2013, 2014) cambió su argumento sobre la desaparición del regionalismo abierto concediendo que se dio solo en algunos

\footnotetext{
4 Veiga y Rios (2007, p. 8) usaron la expresión regionalismo posliberal para referirse al surgido después de 2005 en MERCOSUR y la CSN. Según ellos, el regionalismo abierto se tradujo en políticas comerciales de apertura unilateral (México y Chile) y mayor número de negociaciones externas. Luego de los años noventa, este regionalismo no desaparece en América Latina sino que: "Desaparece a 'convergência liberal' dos anos 90, dando lugar à adoção de estratégias diversas - e inclusive divergentes - de inserção internacional. De um lado, alguns países buscam ampliar sua integração à economia internacional implementando políticas de abertura comercial para bens e serviços e de estabilidade de regras e proteção aos investimentos estrangeiros. [...] De outro lado, consolidou-se um grupo de países que resistem não apenas a realizar movimentos mais expressivos de abertura comercial, mas também a assumir compromissos com regras em serviços e investimentos nos acordos comerciais. Esses são os países que resistem a avançar em negociaçôes com os EUA (Argentina, Brasil, Venezuela e Bolívia)” (p. 17).
} 
países, y distinguió entre multilateralismo discursivo y realmente existente, su caracterización de la CELAC como modalidad multilateral defensiva es confusa porque también la incluye, junto con UNASUR, en la modalidad revisionista.

5. La debilidad del argumento de un trilema propio de América Latina, originado por la presencia de Estados Unidos, reside en que ese mismo trilema se plantea en la UE y podría llegarse a asumir que si América Latina no estuviera en el área de influencia de Estados Unidos no lo enfrentaría.

6. El argumento de los círculos concéntricos en torno de Brasil (MERCosur, UNASUR y CELAC) (Sanahuja, 2012) ignora el rol de otro poder regional (México) que también impulsa la CELAC y tiene sus propios intereses en ella.

En general, estas debilidades derivan de incluir en el concepto de multilateralismo latinoamericano a todos los acuerdos entre tres o más miembros que tienen lógicas distintas que los acuerdos de integración económica.

\section{PROPUESTA DE UN PROCESO DE CONCEPTUALIZACIÓN CONTEXTUALIZADA}

En esta sección se propone un proceso alternativo de conceptualización que recoge las contribuciones de la literatura. Las premisas son que el multilateralismo de las regiones 5 es un fenómeno que se advierte no solo en América Latina. En otras regiones esos acuerdos comparten rasgos del multilateralismo latinoamericano (poca institucionalidad, por ejemplo) pero las variables explicativas y el contexto no son los mismos. Por ejemplo, en Asia-Pacífico la interdependencia económica creó encadenamientos que minimizan la necesidad de una institucionalización fuerte, según el modelo europeo. En América Latina, por el contrario, el voluntarismo político detrás de esos acuerdos y la falta de encadenamientos económicos demandan una institucionalización que no existe (Nicolas, 1997).

La pregunta es qué variables del contexto regional latinoamericano explican el surgimiento de acuerdos multilaterales con las características que tienen. A fin de contestarla se define primero qué acuerdos latinoamericanos se ajustan a los rasgos básicos cuantitativos y cualitativos del multilateralismo, para explicar luego su proceso de surgimiento y desarrollo y por qué asumen los rasgos que tienen.

En esta perspectiva, el multilateralismo en relaciones internacionales se refiere a la actividad institucionalizada y conjunta de varios países en torno a una cuestión específica, lo que determina como base un acuerdo formal. Según la clasificación de la OMC, los acuerdos multilaterales abarcan a la totalidad o la mayoría del universo de actores posibles -de acuerdo con el significado del prefijo "multi”, muchos o numerosos (Goh, 2014)-y los

5 Esta expresión se utiliza para diferenciarlo del multilateralismo regional (Mylonas y Yorulmazlar, 2012). 
plurilaterales, a un número menor de actores ${ }^{6}$. Este criterio cuantitativo se complementa con el hecho de que esos acuerdos permiten a sus miembros participar en otros. Un criterio cualitativo los vincula con el cumplimiento efectivo de los principios que promueven $y$, si no hay cumplimiento, que contribuyan a prevenir la inestabilidad y el conflicto entre Estados (Serbin, 2010, p. 2). En cuanto a la distinción entre multilateralismo tradicional (Estado-céntrico) y complejo (con actores no gubernamentales), aceptamos que, excepto en la retórica, en la región predomina el primero (Legler, 2011, p. 41; Legler y Santa Cruz, 2012, p. 32).

En el ámbito global se consideran acuerdos multilaterales a la Organización de las Naciones Unidas (ONU), la Organización Mundial del Comercio (OMC), el Banco Mundial, el Fondo Monetario Internacional (FMI), entre otros. En América Latina, la CELAC y la UNASUR reúnen las características de incluir a la totalidad o la mayoría de las naciones, permitir la pertenencia a otros acuerdos y, aunque sus normas no sean totalmente acatadas, contribuir a la estabilidad regional y a la proyección externa de la región. Algunos autores consideran multilateral también al ALBA, pero el hecho de que represente a ocho Estados (cuatro en el Caribe, uno en Centroamérica $\mathrm{y}$ tres en Suramérica), de un posible universo de 33, lo ubica fuera del criterio cuantitativo. Otros argumentos en contra son que no es un referente en la agenda internacional a los ojos de actores extrarregionales (Diamint, 2013, p. 75) y su perfil de acuerdo ideológico defensivo y de proyección del Gobierno venezolano, que basa su política exterior en la inevitabilidad del conflicto, no contribuye a la estabilidad ni a la unión regional (Russell, 2006; Giacalone, 2012).

En cuanto al proceso de surgimiento y desarrollo del multilateralismo latinoamericano, desde la perspectiva del sistema internacional, con el paso de la Guerra Fría a la posguerra fría a fines de los años ochenta el conflicto geopolítico global perdió énfasis y resurgieron conflictos regionales postergados o acallados previamente. En paralelo, los poderes mundiales eludieron la responsabilidad de mediar en conflictos regionales y crearon un vacío de poder que fue ocupado por poderes regionales (Lake y Morgan, 1997). Estos últimos, empoderados por factores económicos o materiales (mayor territorio, población, recursos naturales o nivel de desarrollo relativo), aprovecharon para proyectarse en el ámbito extrarregional con la expectativa de cambiarlo y crear acuerdos multilaterales en sus regiones con los cuales ejercer o ampliar su dominio. La crisis del multilateralismo político (ONU) y económico (OMC) también contribuyó a que las regiones desarrollaran respuestas coordinadas a sus problemas transnacionales (Rojas Aravena, 2011, p. 217).

6 Goh (2014) también señala la confusión de usar multilateralismo como equivalente a regionalismo, con lo cual se confunde "el canal de acción" con "la ambición normativa" de que el multilateralismo ayude a desarrollar una identidad y capacidad colectiva regional. 
En la perspectiva regional, la situación actual del multilateralismo latinoamericano surge de un proceso que, aunque puede tener raíces históricas lejanas, se inició en los años noventa. En esa década surgieron acuerdos regionales acotados y concentrados en lo económico, como Mercosur. Además, tanto MERCosur como el Grupo Andino (convertido en CAN en 1995) fueron afectados por la propuesta estadounidense de un Área de Libre Comercio de las Américas (ALCA). Brasil respondió proponiendo un área de comercio suramericana, combinando la institucionalidad y los mercados de can y mercosur. Su estrategia para enfrentar al ALCA se apoyó en el regionalismo económico que aseguraba su dominio regional mediante la protección arancelaria. Mientras tanto, el Grupo Contadora (Colombia, México, Panamá, Venezuela), creado en 1989 para mediar en la crisis centroamericana, cuando esta terminó se orientó a establecer un acuerdo de libre comercio entre Colombia, México y Venezuela (G-3). Este acuerdo de regionalismo abierto incluyó mayor liberalización comercial y temas como propiedad intelectual, servicios, etc.

Para el 2000, la política exterior brasileńa buscaba solucionar problemas que afectaban su desarrollo -la falta de integración física del territorio nacional y la crisis energética ${ }^{7}$-. Para solucionar el primero, promovió el proyecto de integración regional de la infraestructura
(IIRSA), que encontró aliados en sus grandes empresas de construcción, interesadas en internacionalizarse y, para el segundo, buscó el ingreso de Venezuela a mercosur debido a sus recursos petroleros ${ }^{8}$. A principios del siglo XXI, cuando la atención de Estados Unidos se dirigió a otras regiones, alejándose de América Latina, Brasil profundizó y amplió su rol como poder regional desplazando su horizonte del Cono Sur a Suramérica, apoyándose en IIRSA y en la ampliación del MERCOSUR, a fin de alcanzar sus objetivos nacionales.

En la primera década del siglo XxI, la existencia de gobiernos de izquierda en Brasil y Venezuela no alcanza por sí sola a explicar por qué esta agrupó a una constelación de naciones pequeñas en un primer círculo ideológico (ALBA) y a naciones del Caribe y Centroamérica en otro mayor y transaccional (Petrocaribe), mientras Brasil creaba la Comunidad Suramericana de Naciones (CSN) (2004), que en 2008 se convirtió en UNASUR. Ambos se apoyaron en los recursos que generó el boom de las exportaciones de commodities (2003-2008), petróleo en Venezuela y soya en Brasil. En este último, además, la internacionalización de sus empresas y el desarrollo de nuevas tecnologías (etanol) complementaron los recursos de las exportaciones para facilitar su expansión global (Giacalone, 2013a). De esta forma, dos gobiernos de izquierda desarrollaron simultáneamente instrumentos de

El Gobierno brasileńo debió racionar el suministro de electricidad a las industrias entre junio de 2001 y marzo de 2002 (Estudio económico de América Latina y el Caribe 2001-2002, 2002, pp. 119-121).

8 Desde los ańos noventa, el gobierno venezolano trataba de acercarse a Brasil para distanciarse del Gobierno colombiano de Ernesto Samper, por sus lazos con el narcotráfico, y crear un polo de desarrollo económico en el oriente de Venezuela. 
política exterior con objetivos distintos. ALBA, como su nombre lo indica, es una alianza política defensiva entre gobiernos con elementos ideológicos comunes. No actúa colectivamente para arbitrar conflictos sino para defender su permanencia en el poder y obstaculizar a otros actores regionales.

Si MERCosur sirvió para que Brasil surgiera como poder regional, aumentando su poder $\mathrm{y}$ visibilidad internacional, una vez alcanzado cierto reconocimiento el Gobierno brasileño promovió sus intereses nacionales antes que los regionales en el ámbito global. De esta manera, el surgimiento de Brasil como poder regional emergente no representó un cambio de poder global para el regionalismo suramericano, dado que Brasil limitó la institucionalización del MERCOSUR y la UNASUR para no verse constreńido por sus socios regionales (Giacalone, 2013b). Este comportamiento es típico de regiones en donde existe un Estado nacional gigante, en las cuales surge un "regionalismo asimétrico" (Beeson, 2010, p. 329), que hace que ese Estado tienda a utilizar el regionalismo según sus objetivos. En estos casos, las regiones se vuelven instrumentos de las políticas exteriores de poderes regionales que protegen y expanden sus intereses en la región y fuera de ella.

Mientras tanto, los gobiernos no satisfechos ni con el regionalismo económico brasileño (MERCOSUR) ni con la proyección ideológica de Venezuela en la región buscaron alternativas como el Arco del Pacífico Latino- americano (2007), que en 2011 derivó en la Alianza del Pacífico (AP) (Chile, Colombia, México y Perú). En el caso colombiano influyó también que, luego que Venezuela saliera de la CAN y el G-3 en 2006 para negociar su ingreso al MERCOSUR, los problemas políticos entre ella y Colombia escalaron hasta que en 2010 la primera prohibió el ingreso de productos de la segunda (Giacalone, 2014). La AP puede considerarse también una alianza defensiva de gobiernos con similar orientación ideológica pero sus aspiraciones son más económicas que políticas.

En la segunda década del siglo, la CELAC surge como foro de discusión de problemas multilaterales y regionales (cambio climático, tráfico de drogas ilícitas, etc.) donde los países deben concertar posiciones para ser tomados en cuenta fuera de su región?. Su importancia radica en que reconoce a la totalidad (América Latina) sobre propuestas nacionales acotadas por la ideología (ALBA) o por la demarcación política y económica de una Suramérica brasileña. La CELAC complementa políticamente para México el surgimiento de la AP, que vincula a este poder regional con dos poderes secundarios (Chile y Colombia) y un aspirante a tal (Perú) para evadir el control de Brasil, eje de UNASUR, y de Venezuela, que mediante el ALBA ejerce poder de veto sobre temas de la agenda regional.

En esta década, UNASUR no ha "alterado sustancialmente" la polarización política

9 El fin del boom puso de relieve que América Latina ha perdido presencia en el comercio internacional en relación con regiones como Asia-Pacífico. En la década de los cincuenta América Latina y el Caribe representaban $12 \%$ del comercio internacional y Asia-Pacífico, $10 \%$. Actualmente, la primera representa $6 \%$ y la segunda, 35\% (Bartesaghi, 2015, p. 348). 
regional (Borda, 2014, p. 244) y ha perdido dinamismo (Mena Erazo, 2014; Varas, 2010), en especial por su incapacidad para solucionar problemas protagonizados por Venezuela (Mizrahi, 2015; Tokatlián, 2014). En 2015, Chile rechazó tratar sus problemas con Perú en UNASUR y Colombia solo aceptó su mediación en el conflicto fronterizo con Venezuela acompañada por la CELAC. Esto coincide con la existencia de problemas en Brasil como la disminución de la demanda masiva china que ocultó por un tiempo la caída en las exportaciones brasileñas, la pérdida de competitividad de su industria frente a importaciones chinas, el escaso margen de votos del Gobierno (3\%) para ser reelecto en segunda vuelta, y las presiones internas en un contexto inflacionario y de disminución del empleo.

El análisis de los acuerdos como instrumentos de las políticas exteriores de naciones individuales (Diamint, 2013) explica la proliferación de instituciones regionales como resultado de una lucha intrarregional por parcelas de poder. Esta situación surgió del vacío de poder producido por el fin de la Guerra Fría, agudizado por la desatención estadounidense hacia América Latina. Los conflictos regionales crearon la necesidad de acuerdos multilaterales para mantener la estabilidad y la paz. Mientras tanto, la transición del sistema internacional hacia una multipolaridad descentralizada (Garzón, 2015) permite entender la coexistencia de distintos patrones de regionalismo con orientación de adentro hacia afuera (centrada en el poder regional) y de afuera hacia adentro (en poderes extrarregionales) de MERCOSUR y la $\mathrm{AP}^{10}$, respectivamente.

Los acuerdos multilaterales se solapan porque representan intereses geoeconómicos y geopolíticos de distintos poderes regionales (Brasil, México), mientras aspirantes a ejercer ese poder (Venezuela) y poderes secundarios (Chile, Colombia) crean alianzas defensivas distintas de los acuerdos de integración económica. Pero esto no explica por qué el multilateralismo latinoamericano se expresa en organizaciones Estado-céntricas, con baja institucionalidad y alto presidencialismo, como muestra la evolución del MERCOSUR a la CSN y la UNASUR, donde el regionalismo económico de Brasil se combinó con objetivos más amplios en la CSN para terminar en UNAsuR, un regionalismo de "bajo impacto" que facilita su accionar individual extrarregionalmente (Medeiros y Dri, 2013, pp. 42, 44) ${ }^{11}$.

10 La AP agrupa a países cuyos gobiernos mantuvieron después de 2005 el regionalismo abierto como forma de organización preferida para su inserción internacional.

11 En esta década hay mayor pragmatismo en ALBA por la pérdida de los factores materiales en que se basaban las relaciones transaccionales entre Venezuela y sus seguidores, y el fallecimiento de su fundador. El Acuerdo de Complementación Económica (ACE) 70 (Venezuela, Cuba, Bolivia y Nicaragua, 2013) establece un cronograma de liberalización comercial con base en acuerdos bilaterales entre sus miembros, como núcleo de una zona de complementación económica que incluiría a Petrocaribe, CARICOM y MERCOSUR (ALADI, 2013). En la práctica, compromete a la ideología como columna vertebral del ALBA al incluir gobiernos no alineados con las posiciones ideológicas de Venezuela y acerca el ALBA a un acuerdo de integración comercial. 
Los acuerdos regionales asumen distintas formas según la historia económica regional. En Asia-Pacífico, los encadenamientos creados por la interdependencia económica minimizan la necesidad de una institucionalización fuerte. En América Latina, por el contrario, el voluntarismo político de los acuerdos y la falta de encadenamientos económicos necesitan una institucionalización que no existe (Nicolas, 1997), de ahí la importancia de analizar la forma en que Brasil ejerce su rol de poder regional para entender los rasgos de los acuerdos multilaterales latinoamericanos. De su condición de ser el menor de los BRICs (Brasil, Rusia, India, China y Sudáfrica) (poderes emergentes) deriva la necesidad de invertir más recursos políticos en el ámbito global que en el regional, donde su asimetría está asegurada y predomina su renuencia a convertirse en comprador o financista de última instancia para sus vecinos ${ }^{12}$.

Junto con la asimetría, la existencia de poderes regionales secundarios con intereses y objetivos divergentes influyó para que Brasil desestimulara la institucionalización regional, abandonando el objetivo de formar un bloque económico suramericano por el de mantener la estabilidad regional (Malamud, 2011). Asimetría y presencia de poderes secundarios con divergencias entre ellos (Venezuela, Colombia y Chile) son variables explicativas de por qué Brasil prefiere acuerdos multilaterales limitados, pues la primera asegura que no dependa política y económicamente de sus vecinos al actuar globalmente, y la segunda impide que surjan competidores por el poder regional o se formen coaliciones en su contra (Giacalone, 2013b). Esto incide para que los acuerdos multilaterales latinoamericanos tengan baja institucionalidad y alto presidencialismo, dado que no es realista asumir la conformación de un acuerdo de este tipo sin participación de Brasil.

Aunque este análisis se centra en contestar la pregunta acerca de qué variables del contexto regional latinoamericano explican el surgimiento de acuerdos multilaterales y sus características, un elemento adicional del contexto es la situación internacional ya que las regiones constituyen sistemas abiertos (Lake y Morgan, 1997). Luego del comportamiento positivo de las economías latinoamericanas en los primeros ańos posteriores a la crisis de 2008, la desaceleración china en la segunda década de este siglo provee un contexto global negativo para sus exportaciones y para atraer inversión extranjera directa. Este factor afecta incluso a países emergentes como Brasil y México. Mientras tanto, Estados Unidos muestra un relativo mayor interés por la región, que se manifiesta en la negociación de sus relaciones con Cuba, tradicional elemento de fricción con los gobiernos del área. De esta manera, en forma simultánea ha cesado el dinamismo de los procesos económicos globales que dieron origen al boom exportador de commodities en la década anterior y el desinterés de Estados Unidos por la región. Desarrollar estos aspec-

12 Por esa razón, globalmente Brasil usa una narrativa ideológica de cambio, mientras en el ámbito regional combina poder político y económico en asociación con grandes empresas y prefiere el status quo. 
tos del contexto internacional y su relación con el multilateralismo latinoamericano no está entre los objetivos de este artículo, pero son importantes para contextualizarlo y evaluar sus posibilidades futuras, así como lo es también el desarrollo de un escenario multipolar regio-céntrico o descentralizado.

En cuanto a si lo analizado permite afirmar la existencia de un marco analítico propio para el estudio del multilateralismo latinoamericano, para que este exista es necesario mucho más que la observación de algunos rasgos de los acuerdos que se asumen como multilaterales, o la aceptación acrítica de la narrativa gubernamental acerca de los mismos. Esos rasgos y esas narrativas adquieren validez solo si consiguen explicar la realidad regional a la luz de la evolución de las relaciones entre sus actores, ayudando a ubicarla dentro de las perspectivas del sistema internacional. Aunque en la literatura se observan contribuciones para conformar ese marco, estas conviven con interpretaciones parciales, superficiales o confusas, que dejan mucho espacio para futuras reflexiones sobre el tema.

\section{REFERENCIAS}

Acharya, A. (2014) The End of the American World Order. Cambridge: Kindle.

ALAdi (2013). Países del ALba avanzan en la construcción del espacio económico del ALBA utilizando el marco jurídico de la ALADI. Boletín Informativo 10 (julio-agosto). Recuperado de http://www. aladi.org/boletin/espanol/2013/julioAgosto/ Proceso1_05.htm

Bartesaghi, I. (2015) El papel de la Alianza del Pacífico en la dinamización de la agenda externa suda- mericana. En Tremolada Álvarez, E. (ed.). La arquitectura del ordenamiento internacional y su desarrollo en materia económica (pp. 343-363). Bogotá: Universidad Externado de Colombia.

Beeson, M. (2010). Assymetrical Regionalism: China, Southeast Asia and Uneven Development. East Asia 27, 329-343. Recuperado de http://www. chinausfriendship.com

Borda, S. (2014). Multilateralismo en transición: la UNASUR. En Anuario de Integración 10 (pp. 223248). Buenos Aires: CRIEs. Recuperado de http:// www.cries.org/wp-content/uploads/2014/11/9Borda.pdf

Buzan, B. (2004). The United States and the Great Powers: World Politics in the Twenty-First Century. Cambridge: Polity Press.

Chen, L. y De Lombaerde, P. (2014). Testing the Relationships between Globalization, Regionalization and the Regional Hubness of the BRICs. Journal of Policy Modeling, 36 (1), 111-131.

Diamint, R. (2013). Regionalismo y posicionamiento suramericano: UNASUR y ALBA. Revista CIDOB dÁfers Internacionals 101, 55-79. Recuperado de www.raco.cat/index.php/RevistacıDoв/article/ download/264160/351801

Dingwerth, K. y Pattberg, P. (2006). Global Governance as a Perspective on World Politics. Global Governance, 12, 185-203.

CEPAl (2002). Estudio económico de América Latina y el Caribe 2001-2002 Santiago de Chile: CEPAL.

Garzón, J. F. (2015). Multipolarity and the Future of Regionalism: Latin America and Beyond. Hamburg: GIGA Working Paper 264. Recuperado de http:// giga-hamburg.de/en/team/garzon

Giacalone, R. (2012). Venezuelan Foreign Policy: Petrodiplomacy and Political Change. En Beasley, J. y Kaarbo, R. (eds.). Foreign Policy in Comparative Perspective. Domestic and International Influences 
on State Behavior. Washington, D.C.: Sage Publications.

Giacalone, R. (2013a). Cooperación Sur-Sur y empresas en Brasil y Chile. Integración y Comercio, 36, 81-97.

Giacalone, R. (2013b). Cambios en el regionalismo sudamericano por la proyección global de Brasil. Aldea Mundo, 36, 9-21.

Giacalone, R. (2014). Cambios en el regionalismo de Colombia y Venezuela (1990-2013): Del Grupo de Los Tres al ALba y la Alianza del Pacífico. En Mellado, N. (ed.). Regionalismo Latinoamericano: Dimensiones Actuales. Córdoba, Argentina: Editorial Lerner.

Goh, E. (2014). AsEAN-led Multilateralism and Regional Order: The Great Power Bargain Deficit. Special Forum, May 23. Recuperado de http://www. theasanforum.org/asean-led-multilateralism-andregional-order-the-great-power-bargain-deficit/

Iapadre, L. y Tajoli, L. (2014). Emerging Countries and Trade Regionalization. A Network Analysis. Journal of Policy Modeling, 36 (1), 89-110.

Lake, D. A. y Morgan, P. M. (1997). Introduction. En Lake, D. A. y Morgan, P. M. (eds.). Regional Orders: Building Security in a New World (pp. 3-18). University Park: Pennsylvania State University Press.

Legler, T. (2011). De la afirmación de la autonomía a la gobernanza autónoma: el reto de América Latina y el Caribe. En Rojas Aravena, F. (ed.). América Latina y el Caribe: multilateralismo vs. soberanía: la construcción de la Comunidad de Estados Latinoamericanos y Caribeños (pp. 23-47). Buenos Aires: Teseo-flacso.

Legler, T. y Santa Cruz, A. (2011). El patrón contemporáneo del multilateralismo latinoamericano. Pensamiento Propio, 16, 11-34.
Llenderrozas, E. (2013). Política exterior latinoamericana y la CELAC. Austral: Revista Brasileira de Estratégia y Relaçôes Internacionais, 2 (4), 183-205.

Malamud, A. (2011). A Leader without Followers? The Growing Divergence between the Regional and Global Performance of Brazil. Latin American Politics and Society 53 (3), 1-24.

Malamud, C. (2015). Integración y cooperación regional en América Latina: diagnóstico y propuestas. Madrid: Real Instituto Elcano.

Mattli, W. (1999). The Logic of Regional Integration: Europe and Beyond. Cambridge: Cambridge University Press.

Medeiros, M. de Almeida y Dri, C. F. (2013). Which Brazilian Policy for Regionalism? Discourse and Institutional Development in Mercosur. Estudios Internacionales, 175, 41-61.

Mena Erazo, P. (2014). ¿Es suficiente un nuevo edificio para relanzar a unasur? BBC Mundo. Recuperado de http://bbc.com/mundo/noticias/2014/12/141204_lujosa_sede_unasur_ac

Mizrahi, D. (2015) Por qué la UNASUr no condena ni va a condenar la represión de Maduro en Venezuela. Infobae America. Recuperado de http://www. infobae.com/2015/04/10/1721438-por-que-launasur-no-condena-ni-va-condenar-la-represionmaduro-venezuela

Mylonas, H. y Yorulmazlar, E. (2012). CNN Special January 14. Recuperado de http://globalpublicsquare.blogs.cnn.com/2012/01/14/regionalmultilateralism-should-be-the-next-paradigmin-global-affairs/

Nicolas, F. (1997). Analyse économique comparative de la regionalisation en Asie et en Amérique latine. Politique Etrangère, (2), 291-307.

Rojas Aravena, F. (2011). Introducción. En América Latina y el Caribe: multilateralismo vs. Soberania: la construcción de la CELAC. Buenos Aires: Flacso. 
Rojas Aravena, F. (2012). América Latina y el Caribe. Vinculos globales en un contexto multilateral. Buenos Aires: Teseo.

Russell, R. (2006). La integración en América Latina. Recuperado de http://www.flacsoandes.edu.ec/ biblio/catalog/resGet.php?resId=19800

Sanahuja, J. A. (2012). El regionalismo post-liberal y el multilateralismo en Sudamérica: el caso de unasur. En Serbín, A., Martínez, L. y Ramanzini Junior, H. (eds.). Anuario de Integración 9 (pp. 19-72). Buenos Aires: Cries.

Sanahuja, J. A. (2013). Narrativas del multilateralismo: "efecto Rashomon" y cambio de poder. Revista CIDOB d'Afers Internacionals, 101, 27-54.

Sanahuja, J. A. (2014). Enfoques diferenciados y marcos comunes en el regionalismo latinoamericano: Alcance y perspectivas de unasur y Celac. Pensamiento Propio, 39, 75-108.

Serbin, A. (2010). Los desafíos del multilateralismo en América Latina. En Martínez Alfonso, L., Ra- manzini Junior, H. y Vázquez, M. (eds.). Anuario de Integración 8 (pp. 7-24). Buenos Aires: CRIES.

Tokatlián, J. G. (2014). UNASUR pierde el norte? El Pais. Recuperado de http://elpais.com/ elpais/2014/04/23/opinion/1398278994 _215974.html

Varas, A. (2010). El lío de la integración en América Latina. Recuperado de http://www.project-syndicate. org/commentary/latin-america-s-integrationmuddle/spanish

Veiga, P. da Motta y Rios, S. P. (2007). O regionalismo pós-liberal, na América do Sul: origens, iniciativas e dilemas. Santiago de Chile: CEPAL. Recuperado de http:// repositorio.cepal.org/bitstream/handle/11362/4428/S2007612_pt.pdf?sequence=1 Yakovleva, N. (2014). Latin American integration in the mirror of Mercosur. Russian Council. Latin America and the Caribbean/Analysis. Recuperado de http://russiancouncil.ru/en/inner/?id=4277 